\title{
Soil-Structure Interaction in the Seismic Response of an Isolated Three Span Motorway Overcrossing Founded on Piles
}

\author{
Francesca Dezi \\ D.E.T., University of San Marino, San Marino \\ Sandro Carbonari \\ D.A.C.S., Marche Polytechnic University, Ancona, Italy
}

Alessandro Tombari

D.A.C.S., Marche Polytechnic University, Ancona, Italy

Graziano Leoni

SAD, University of Camerino, Ascoli Piceno, Italy

Keywords: Base isolation, bridges, pile foundations, site effects, soil-structure interaction.

\begin{abstract}
:
The effects of soil-structure interaction on the seismic response of an isolated three span motorway overcrossings founded on piles are investigated by considering a real bridge located along the A14 Motorway in central Italy. The dynamic and mechanical properties of the soils are obtained from a comprehensive geotechnical characterization of the sites. Ten triplets of real accelerograms, defined at the outcropping bedrock, are adopted and processed by local response analyses to capture the site amplification effects and the free-field motions within the deposits. The soil-structure interaction effects are evaluated by means of the substructure method by comparing the seismic response of the structures with those obtained from conventional fixed base models. Analyses demonstrate that the soil-foundation dynamic compliance as well as the energy loss due to radiation damping dot not modify significantly the overall behaviour of the isolated bridges, while soil-structure interaction may increase deformations and forces on the isolation devices with respect to those obtained with fixed base models.
\end{abstract}

\section{INTRODUCTION}

The usual seismic design of structures is based on the ductility concept, namely on the structural capability of undertaking plastic deformations, without significant loss of resistance, and dissipating energy by hysteresis through structural damages. Even if the structure failure is prevented, significant repairs are generally necessary after strong earthquakes.

By using isolation devices, the motion of the ground can be uncoupled from the structure letting the structure vibrate mainly with rigid modes reducing seismic internal forces in the structural elements. The simplicity in the design and the installation of the devices makes the base seismic isolation a very interesting strategy to reduce structural damages due to earthquakes, particularly suited for constructions whose functionality after earthquakes must be assured (e.g., structures important for civil protection). In this framework, the use of base isolation is becoming frequent also for bridges where the seismic devices are generally placed at the top of piers.

The most popular isolator devices are those based on High Damping Rubber (HDR) that is a natural rubber compound to which a filler is added to improve some of its properties such as stiffness and dissipation capacity. The performance of HDR devices depends on the shear strain that is a function of the relative displacements and rotations between the top and the bottom plates of the isolators, as well as of the axial force. 
Many works are available in the literature dealing with the seismic performance of isolated bridges [1-4] but only few of them account for the foundation compliance [5-7]. Soil-Structure Interaction (SSI) and site effects may be important in the design of isolated bridges since the actual flexibility of the soil-foundation system, combined with site amplification effects, may modify the whole dynamic response and increase the shear strains of isolators.

In this work site amplification and SSI effects on the seismic response of an isolated overcrossing founded on piles are investigated. Five equal real bridges, located along the A14 Motorway in central Italy, are considered. The soil stratigraphies are constituted by marine deposit prevalently composed of marly clay with a thickness of hundreds of meters underlying a continental covering soil of variable thickness. At the five locations the soil profiles are different in the upper layers so that the seismic action as well as the base compliance may affect the behaviour of the bridges in a different way despite the seismic hazard of the region is the same.

SSI analyses are carried out with the substructure method. Multiple independent site response analyses at each pier and abutment location are carried out before performing the kinematic interaction analysis in the frequency domain. Site response analyses allow computing the free-field input motions starting from real accelerograms opportunely defined at the outcropping bedrock. The inertial interaction analysis of the each superstructure is performed in the time domain by means of a 3D finite element model adopting Lumped Parameter Models (LPMs) to account for the compliance of each soil-foundation systems (piers and abutments). The procedure is adopted to investigate the effects of SSI and site amplification on the seismic response of the case studies, comparing the obtained results with those derived from conventional fixed base models. Furthermore, in order to highlight differences with non-isolated bridges, fixed base and SSI analyses are performed on the same bridge redesigned according to a conventional approach.

\section{CASE STUDIES}

Most of new overcrossings designed for the construction of the A14 Motorway third lane in Central Italy (Figure 1a) are seismically isolated and characterised by the structural scheme shown in Figure 1b. The deck has a total length of $80 \mathrm{~m}$ and is divided into three spans of 21,38 and $21 \mathrm{~m}$; the steel-concrete composite deck is $11 \mathrm{~m}$ wide and is constituted by a $0.24 \mathrm{~m}$ thick slab and three steel I-shaped girders with variable depth. Both piers are equipped with three HDRBs while multidirectional sliding bearings are placed at the abutments. HDRBs are characterized by an effective horizontal stiffness $\mathrm{k}_{\text {eff }}=2010 \mathrm{~N} / \mathrm{mm}$ and an equivalent damping factor $\xi=10 \%$ so that the fundamental period of the isolated bridge is about $2.0 \mathrm{~s}$. Piers and abutments are founded on 1.2 $\mathrm{m}$ diameter bored concrete piles with lengths depending on the soil profile (Figure 2). The bridges and the isolation system are designed according to Italian Standards [8].

The geological configuration of the sites where the bridges are located is constituted by two main formations: a Plio-Pleistocene marine deposit prevalently composed of marly clay with a thickness of hundreds of meters underlying a Quaternary (Holocene-Pleistocene) continental covering soil of variable thickness (generally not greater than $40 \mathrm{~m}$ ) that mainly consists of alluvial, eluvialcolluvium and coastal deposits. Sometimes, the marine Plio-Pleistocene marly clay crops out presenting a weathered layer at its upper part.

As the covering deposit has a variable depth and sometimes is constituted by different soils, it is interesting to study the effects of the local geology and of the kinematic interaction on the behaviour of the bridges that are built with the same kind of structure. For this purpose, five bridge locations, characterised by different soil stratigraphies, are considered (Figure 1a). A large number of laboratory tests (such as oedometer, triaxial and simple shear test) and in-situ tests (dilatometer Marchetti, cone penetrometer, piezocone, standard penetrometer, multichannel analysis of surface waves and cross hole) have been carried out for the characterization of the soil. In this paper the five soil profiles (S\#) deduced from borehole investigations and depicted in Figure 2a are 
considered. Figure $2 \mathrm{~b}$ shows the profiles of shear wave velocities $\mathrm{V}_{\mathrm{s}}$ defined on the base of direct measurements and according to available geological and geotechnical information (solid line). When no direct site seismic measurements are available, the $\mathrm{V}_{\mathrm{s}}$ profile (dashed line) has been derived from geological and geotechnical information combined with direct seismic measurements performed in similar sites located in the same region. In particular, the $\mathrm{V}_{\text {s }}$ profile within the marly clay stratum is assumed to vary linearly by considering a gradient of about $6 \mathrm{~m} / \mathrm{s} / \mathrm{m}$ up to the "seismic bedrock" (Figure 2b). From boreholes, the position of the "seismic bedrock" $\left(\mathrm{V}_{\mathrm{S}}>800 \mathrm{~m} / \mathrm{s}\right)$ is never detected. The maximum shear wave velocity measured in the intact marly-clay formation is about $600 \mathrm{~m} / \mathrm{s}$. According to Facciorusso e Madiai [9], the "seismic bedrock" is assumed in the marly-clay formation at the depth corresponding to a shear wave velocity of $600 \mathrm{~m} / \mathrm{s}$. The soil mechanical properties are reported in Table 1. Figure $2 \mathrm{c}$ and $\mathrm{d}$ show also the shapes of the firsts two vibration modes of the deposits and the amplification functions defined at the outcropping soil (level A) and at the top of the marly clay stratum (level B), demonstrating how the different strata affect the amplification of the seismic action within the soil profile. It is worth noting that, according to the soil classification proposed by the Italian code [8], based on the shear wave velocity $\mathrm{V}_{\mathrm{s}, 30}$ referred to the top 30 metres of the ground, all the profiles fall within the soil type $\mathrm{C}$.

(a)
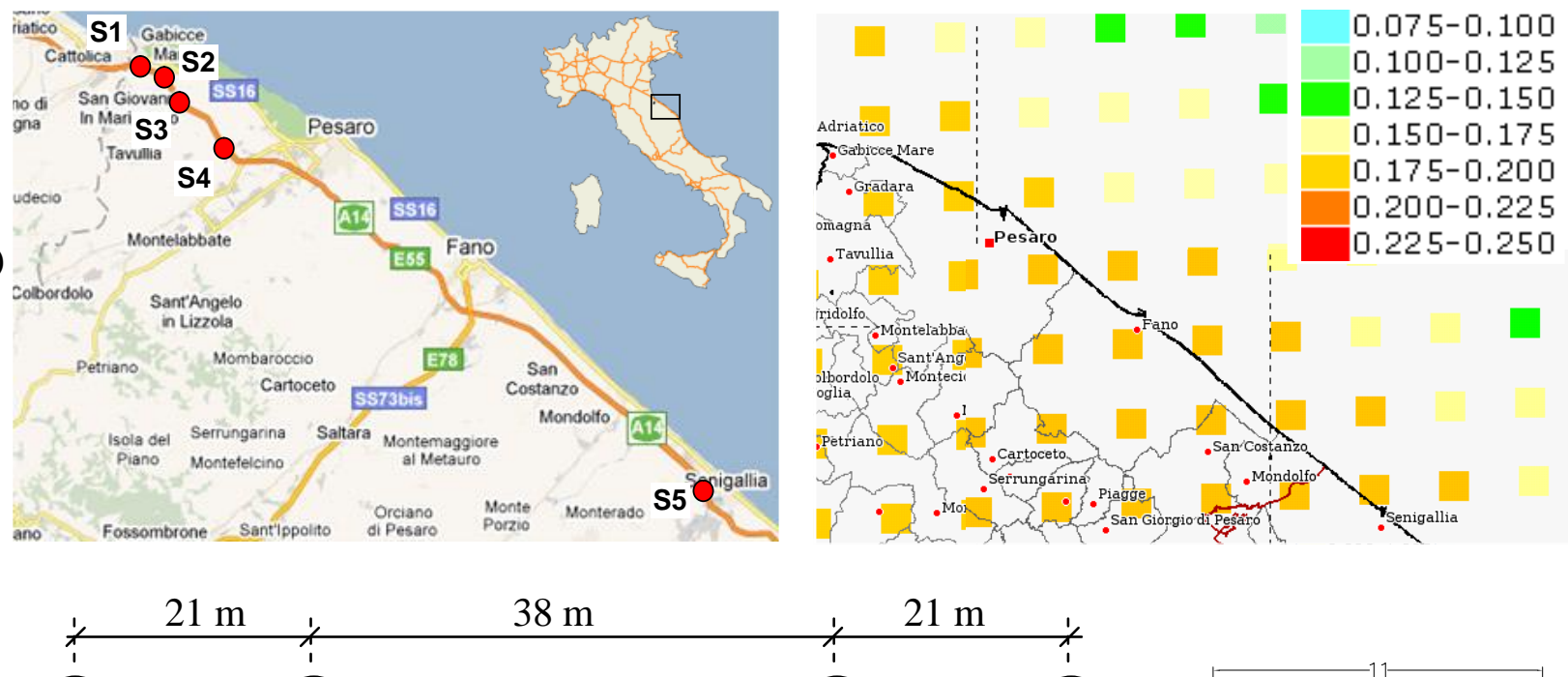

(b)
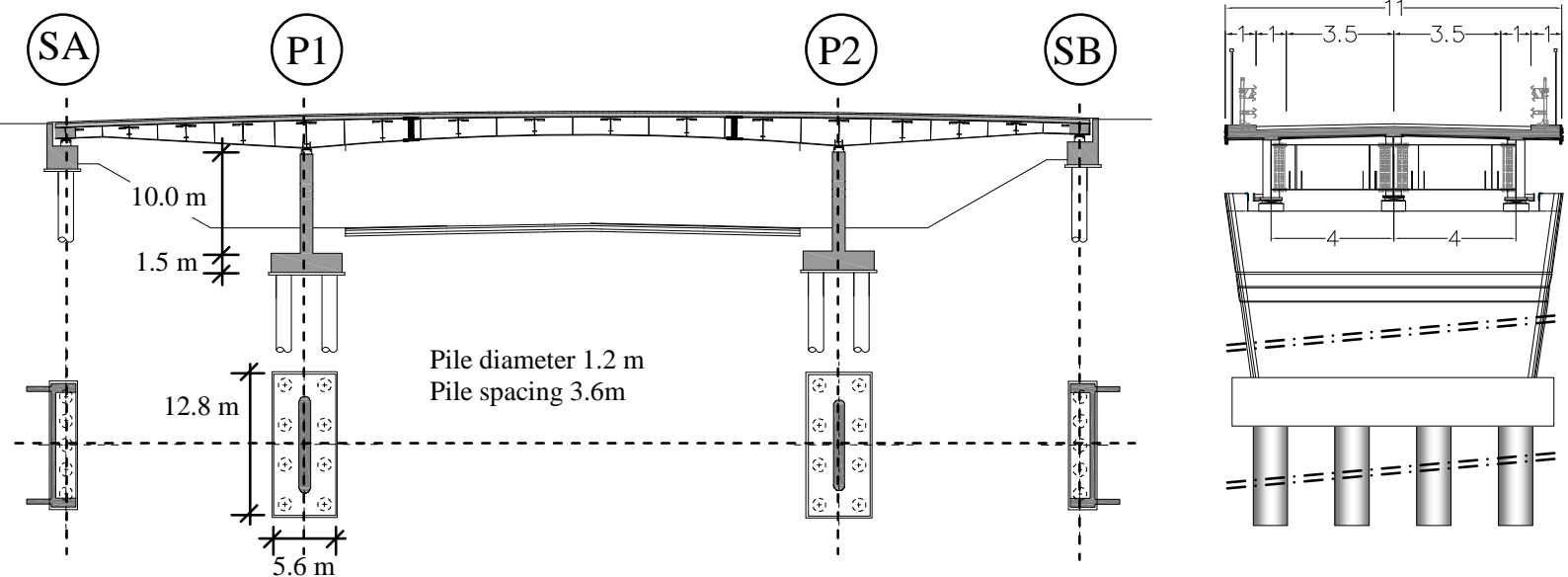

Figure 1. (a) Locations of the considered bridges and PGA [g] hazard map (return period 475 years); (b) scheme of the bridges 

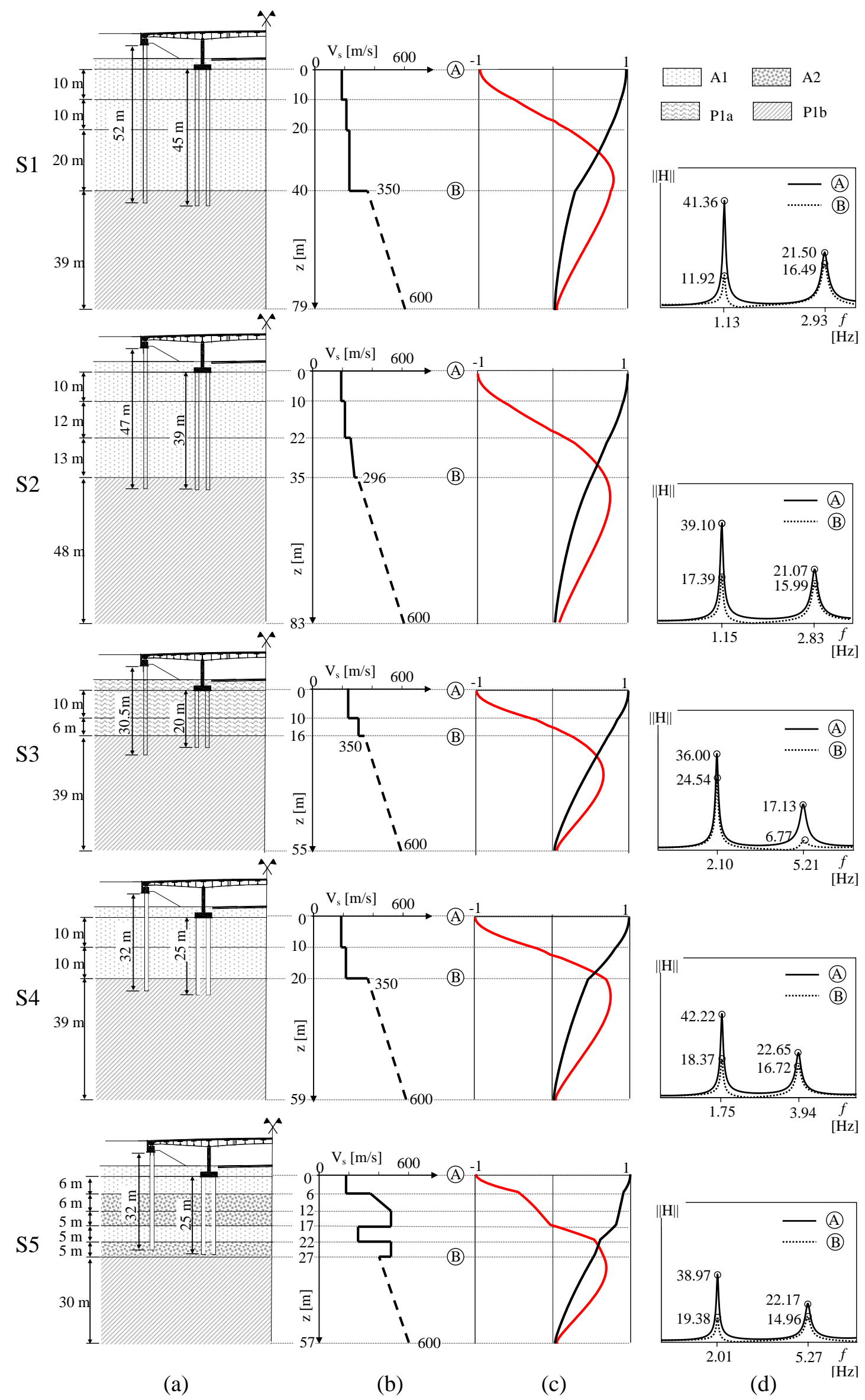

Figure 2. (a) soil profiles; (b) $V_{s}$ profiles; (c) shapes of the first two vibration modes; (d) amplification functions 
Table 1: Soil properties estimated from available data

\begin{tabular}{lccccccc}
\hline & $\begin{array}{c}\gamma_{\mathrm{t}} \\
\text { Soil layers }\end{array}$ & $\begin{array}{c}\varphi^{\prime} \\
{\left[\mathrm{Mg} / \mathrm{m}^{3}\right]}\end{array}$ & $\begin{array}{c}\varphi^{\prime} \\
{\left[{ }^{\circ}\right]}\end{array}$ & $\begin{array}{c}\mathrm{c}^{\prime} \\
{\left[{ }^{\circ}\right]}\end{array}$ & $\begin{array}{c}\mathrm{kPa}] \\
\text { OCR }\end{array}$ & $\begin{array}{c}\mathrm{C}_{\mathrm{u}} \\
{[\mathrm{kPa}]}\end{array}$ \\
\hline P1a & Weathered marly clay & $19 \div 21$ & - & $23 \div 28$ & $11 \div 22$ & 5 & $15 \cdot \mathrm{z}^{-0.4}$ \\
\hline P1b & Intact marly clay & $19.5 \div 21.5$ & - & $26 \div 28$ & $16 \div 22$ & $5 \div 10$ & $>6$ \\
\hline A1 & Silty clay deposit & $19 \div 20$ & - & $22 \div 29$ & $18 \div 24$ & 5 & $12 \cdot \mathrm{z}^{-6}$ \\
\hline A2 & Gravelly sand deposit & 19.5 & $40 \div 70$ & $37 \div 40$ & - & - & 1 \\
\hline
\end{tabular}

Table 2: Earthquake records adopted in the analyses

\begin{tabular}{|c|c|c|c|}
\hline Earthquake & $\begin{array}{l}\text { Transducer } \\
\text { Orientation }\end{array}$ & $\begin{array}{l}\text { PGA } \\
{\left[\mathrm{m} / \mathrm{s}^{2}\right]}\end{array}$ & $\begin{array}{l}\mathrm{M}[\mathrm{Mw}] \\
\text { Durat. [s] }\end{array}$ \\
\hline $\mathrm{R} 1$ & $\mathrm{~N}-\mathrm{S}$ & 0.628 & \multirow{3}{*}{$\begin{array}{c}5.9 \\
32.44\end{array}$} \\
\hline Lazio-Abruzzo & E-W & 0.671 & \\
\hline Italy (1984) & VERT & 0.256 & \\
\hline $\mathrm{R} 2$ & N90E & 0.360 & \multirow{3}{*}{$\begin{array}{c}5.9 \\
20.01\end{array}$} \\
\hline Chenоuа & N180 & 0.343 & \\
\hline Algeria (1989) & VERT & 0.210 & \\
\hline $\mathrm{R} 3$ & NS & 0.246 & \multirow{3}{*}{$\begin{array}{c}5.2 \\
20.15\end{array}$} \\
\hline Umbria-Marche & WE & 0.187 & \\
\hline Italy (1997) & DU & 0.166 & \\
\hline $\mathrm{R} 4$ & LONG & 0.138 & \multirow{3}{*}{$\begin{array}{c}6.0 \\
35.98\end{array}$} \\
\hline Mt. Vatnafjoll & TRAN & 0.131 & \\
\hline Iceland (1987) & VERT & 0.071 & \\
\hline R5 & $\mathrm{N}-\mathrm{S}$ & 0.302 & \multirow{3}{*}{$\begin{array}{c}6.4 \\
48.60\end{array}$} \\
\hline Kalamata & E-W & 0.339 & \\
\hline Greece (1997) & VERT & 0.163 & \\
\hline
\end{tabular}

\begin{tabular}{|c|c|c|c|}
\hline Earthquake & $\begin{array}{l}\text { Transducer } \\
\text { Orientation }\end{array}$ & $\begin{array}{l}\text { PGA } \\
{\left[\mathrm{m} / \mathrm{s}^{2}\right]}\end{array}$ & $\begin{array}{c}\mathrm{M}[\mathrm{Mw}] \\
\text { Durat. [s] }\end{array}$ \\
\hline R6 & $\mathrm{N}-\mathrm{S}$ & 0.212 & \multirow{3}{*}{$\begin{array}{c}6.0 \\
29.04\end{array}$} \\
\hline Umbria-Marche & E-W & 0.204 & \\
\hline Italy (1997) & VERT & 0.151 & \\
\hline R7 & $\mathrm{N}-\mathrm{S}$ & 0.588 & \multirow{3}{*}{$\begin{array}{c}6.9 \\
66.50\end{array}$} \\
\hline Campano Lucano & E-W & 0.588 & \\
\hline Italy (1980) & VERT & 0.344 & \\
\hline $\mathrm{R} 8$ & LONG & 0.302 & \multirow{3}{*}{$\begin{array}{c}6.0 \\
35.98\end{array}$} \\
\hline Mt. Vatnafjoll & TRAN & 0.339 & \\
\hline Iceland (1987) & VERT & 0.163 & \\
\hline $\mathrm{R} 9$ & $\mathrm{~N}-\mathrm{S}$ & 3.499 & \multirow{3}{*}{$\begin{array}{c}6.5 \\
36.53\end{array}$} \\
\hline Friuli & E-W & 3.097 & \\
\hline Italy (1976) & VERT & 2.623 & \\
\hline R10 & LONG & 0.160 & \multirow{3}{*}{$\begin{array}{c}5.9 \\
10.89\end{array}$} \\
\hline Tithorea & TRAN & 0.210 & \\
\hline Greece (1992) & VERT & 0.168 & \\
\hline
\end{tabular}
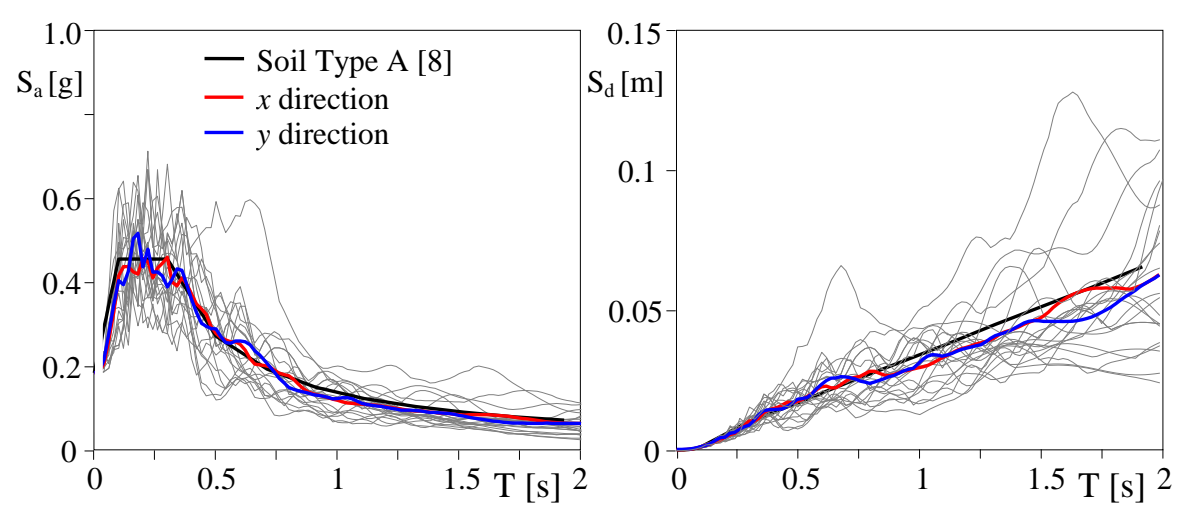

Figure 3. Spectra at outcropping bedrock: pseudo-acceleration and displacement

\subsection{Seismic action}

The region is a medium seismicity area, namely characterised by frequent events of medium local macroseismic intensity, due to seismic activity originating from the central part of the Apennine mountains where several seismogenetic sources are present especially close to the Adriatic coast [10]. By considering a return period of 475 years, the rock outcropping PGA $(0.18 \mathrm{~g})$ and the relevant response spectrum are suitably selected taking into account information from the Italian seismic hazard map [11] (Figure 1a). In order to compare results of the analyses carried out with the different profiles, the seismic input, defined at the bedrock, is the same for each deposit even if some discrepancies may exist with the local hazard. Ten triplets (horizontal and vertical directions) of real accelerograms are selected from the European Strong Motion Database [12] and considered for the seismic site response analyses (Table 2). Figure 3 shows the elastic pseudo-acceleration and displacement response spectra of the horizontal components of the selected accelerograms; the 
mean spectra obtained for the two orthogonal directions are also shown and compared with the reference spectra proposed by the Italian Seismic code [8]. The horizontal components of the seismic inputs are assumed to act along the longitudinal $(x)$ and transverse $(y)$ directions of the bridge.

\subsection{Site analysis}

Due to the prevalently flat site geo-morphology, and to the low-to-medium strain levels expected, a 1D linear method is adopted to investigate the seismic site response and capture the local amplifications due to the covering deposit. To take into account soil nonlinearity, suitable shear modulus degradation and damping ratio curves are used in the linear analysis to define the soil properties according to the maximum shear strain experienced by the soil during the earthquake. For soils A1, P1a and P1b (see Table 1) experimental curves obtained by Crespellani and Simoni [13] are adopted whereas for soil A2 (mainly gravelly sands) curves proposed by Vucetic and Dobry [14] for $I_{p}=0 \%$ are considered (Figure 4). Furthermore, in order to investigate the site response sensitivity to the nonlinear behaviour of the soil, analyses with the low-strain properties are also carried out.

Figure 5 shows the mean displacement response spectra at the ground surface of the five profiles (in the $x$ and $y$ directions) compared with the spectrum provided by the Italian Seismic Code for soil type C [8]. Furthermore, the mean displacement response spectrum relevant to the outcropping bedrock is also reported with a black continuous line. It is worth noting how the code response spectrum essentially captures the results of the local analysis providing a good estimation of the maximum displacements within the range of the fundamental vibration periods of each deposit (pointed out by the frequency response functions reported in the same figure). However, the type $\mathrm{C}$ spectrum largely overestimates the response of the specific sites for higher periods. This result reveals the importance of performing a reliable site response analysis for the evaluation of the seismic action for structures. In particular, for isolated bridges, characterized by high fundamental periods, the code spectrum may overestimate significantly the seismic action if the fundamental period of the deposit is far from the structural one. This may lead to oversize the isolation system as well as the bridge expansions joints.

It is worth noting that the nonlinear behaviour of the soil affects sensibly the site response of profiles S1, S2 and S4, characterised by thick deposits with $\mathrm{V}_{\mathrm{s}}$ less than $200 \mathrm{~m} / \mathrm{s}$, whereas profiles $\mathrm{S} 3$ and S5 are less sensitive to the degradation of the shear modulus.

The time histories obtained from the site analyses are used in the SSI analyses as free-field motion at the ground surface and at different depths within the deposit along piles.
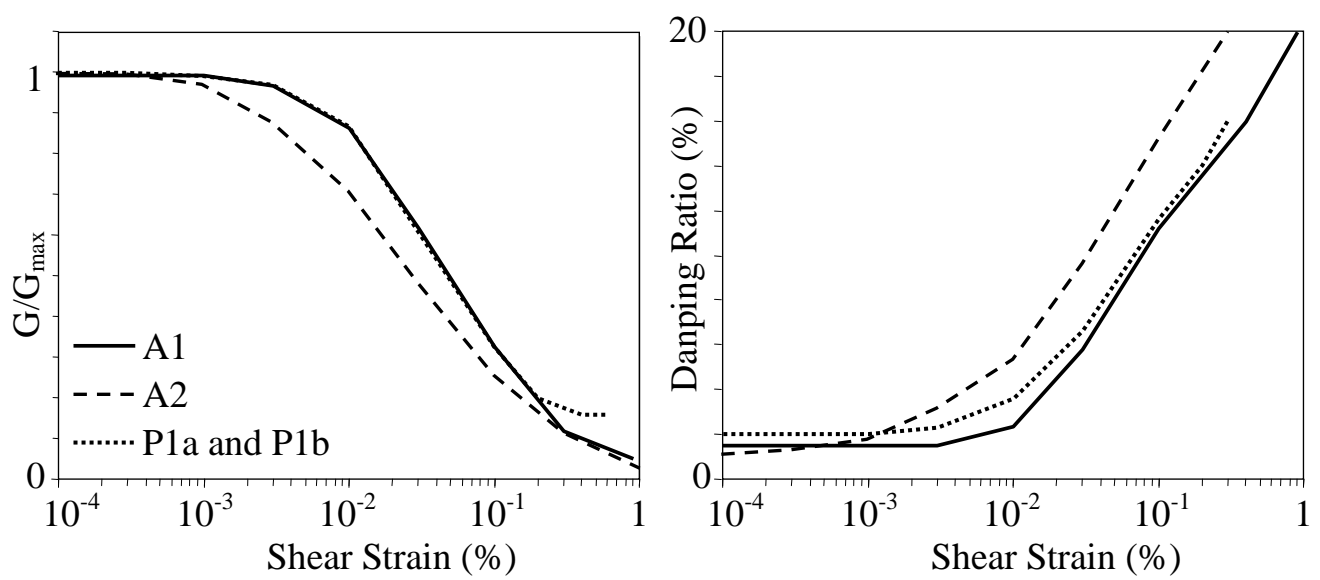

Figure 4. Normalized shear modulus and damping ratio curves 
S1
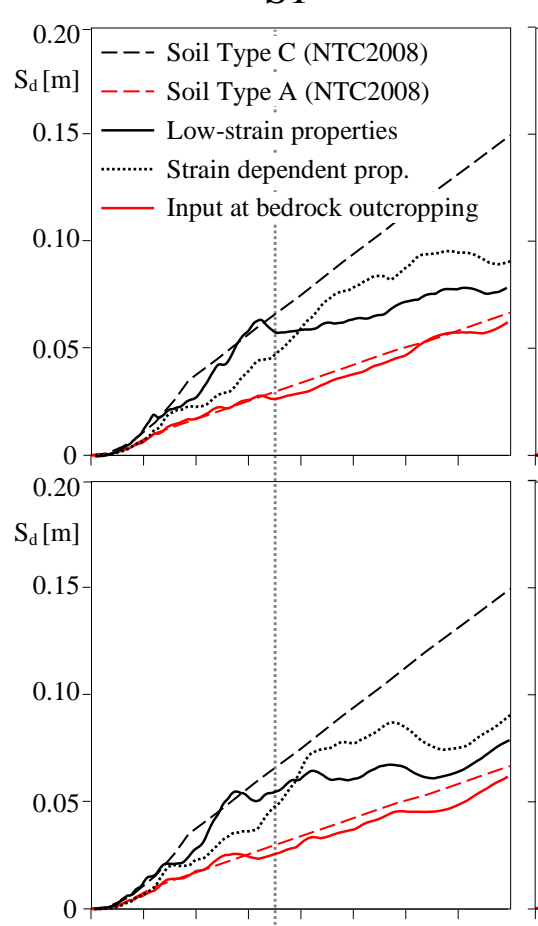

1.2

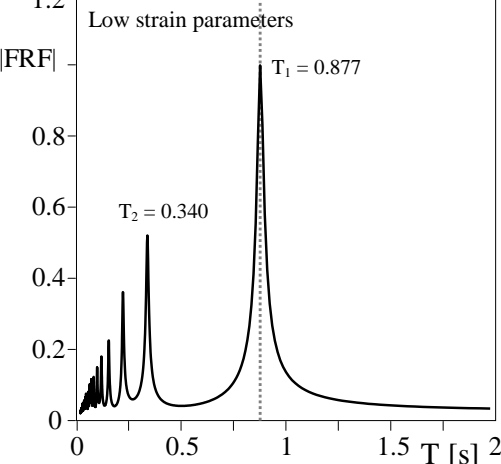

S2
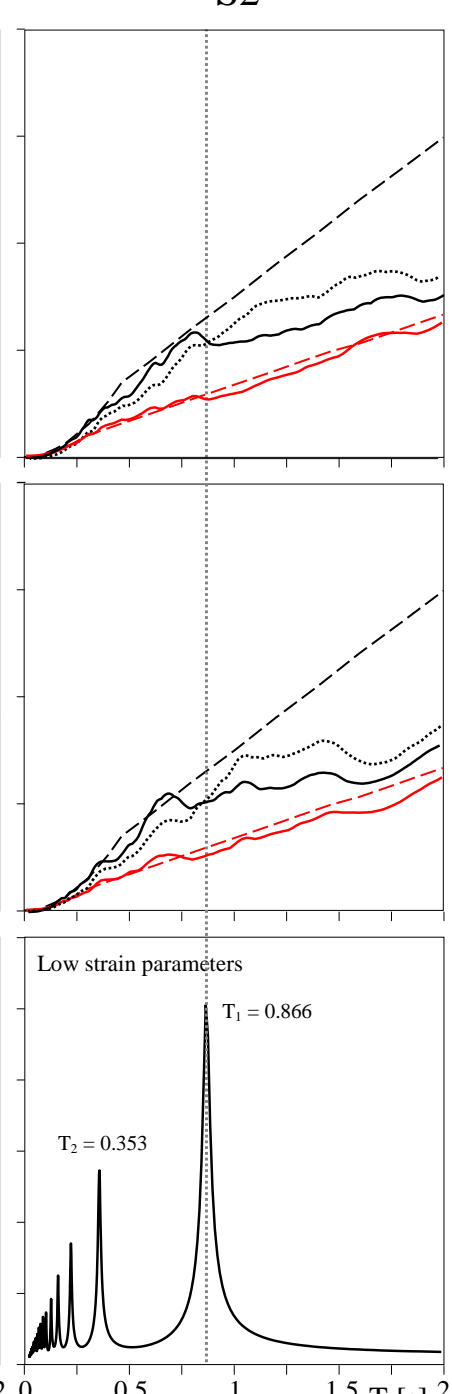

S3
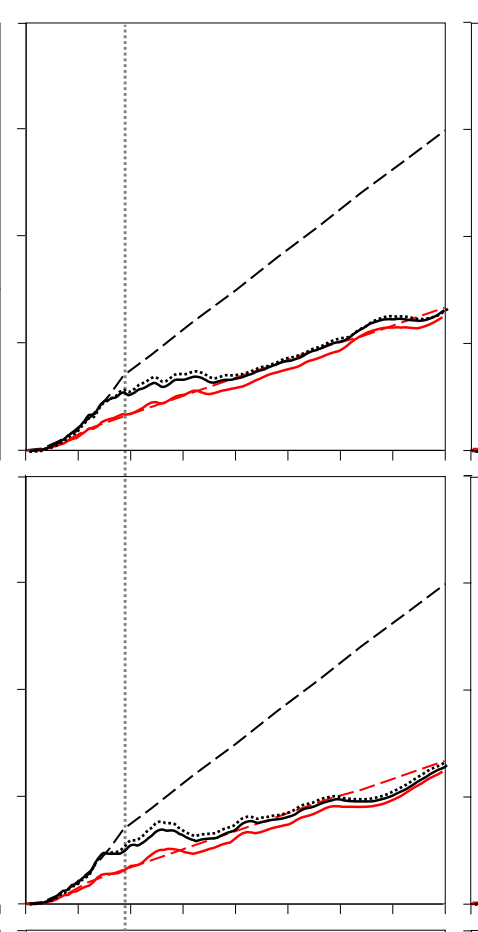

Low strain parameters

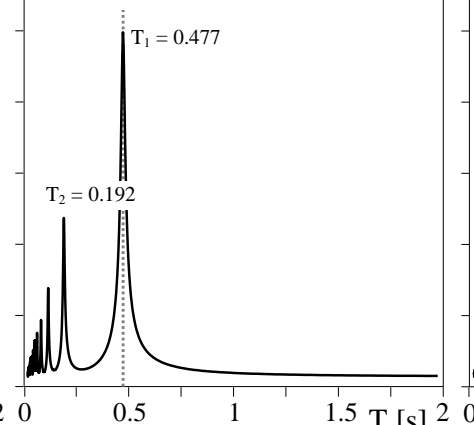

S4
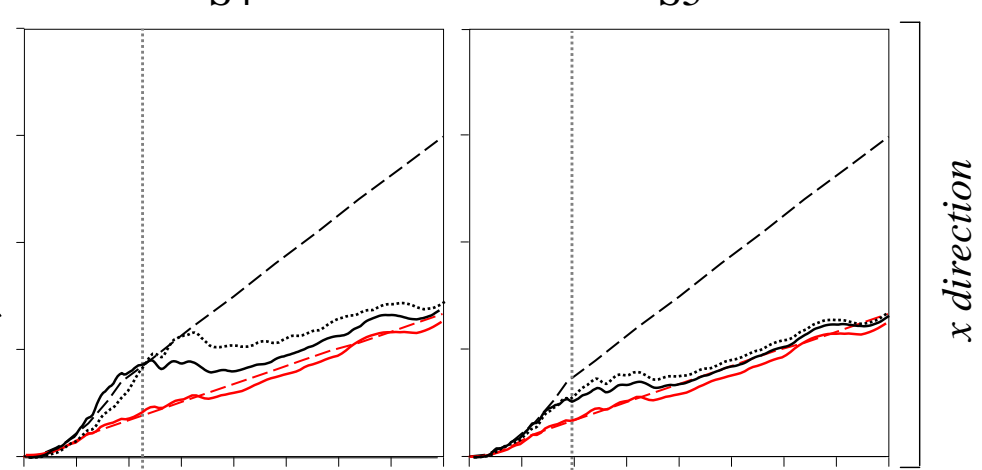

\section{1}
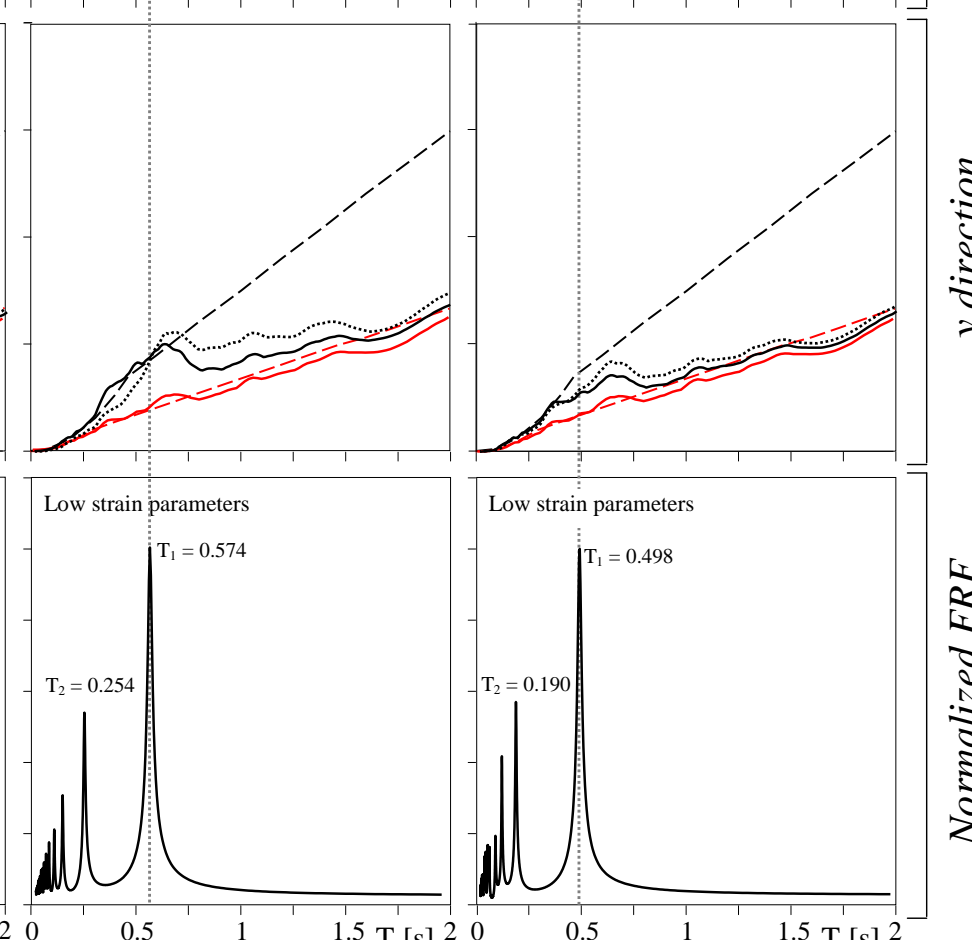

Low strain parameters

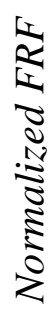

Figure 5. Mean displacement response spectra at outcropping bedrock and ground surface compared with reference spectra 

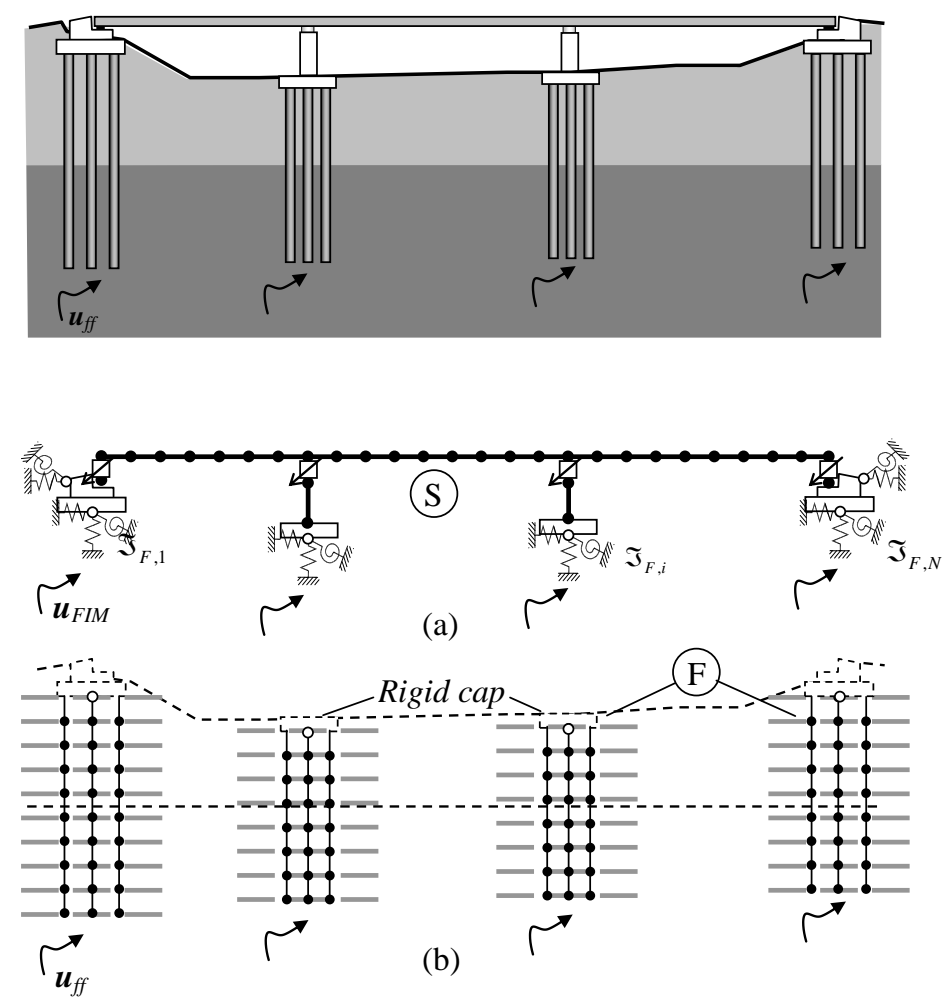

Figure 6. Substructure approach: (a) bridge on compliant base and (b) soil-foundation system

\section{SSI ANALYSIS OF THE ISOLATED BRIDGES}

For the presence of the isolation system, the structure is not expected to undergo damage and the SSI problem may be conveniently studied with the substructure method under the assumption of linear behaviour for both soil and structure [15] (Figure 6).

In a first step, the analysis of the soil-foundation system (kinematic interaction analysis) is carried out in the frequency domain by means of the numerical procedure proposed by Dezi et al. [16] in which the transient motion, obtained from the site analysis, is used as seismic input. These analyses provide the foundation input motion and the frequency dependent impedances of the soil-foundation systems.

In the second step, the superstructure analysis (inertial interaction analysis) is performed in the time domain by means of a commercial finite element computer program, in which the foundation input motion is used as seismic action and the soil-foundation impedances define the restraint system.

\subsection{Analysis of the soil-foundation system}

The analysis of the pile group foundations is performed by considering piles as beams embedded in a generic horizontally layered half-space constituted by independent horizontal infinite layers (Figure 6b) where in-plane and out-plane waves can propagate [16] so that pile-to-pile interaction and radiation damping are captured.

With reference to the specific cases considered in this paper, $1 \mathrm{~m}$ long finite elements are used to discretize each pile to achieve a good level of accuracy. The pile density is $2.5 \mathrm{Mg} / \mathrm{m}^{3}$ and the modulus of elasticity is $2.4 \times 10^{4} \mathrm{~N} / \mathrm{mm}^{2}$ to take into account the concrete cracking. The foundation cap is modelled by introducing a rigid body geometric constraint with the master node placed at the centroid of pile group head. The kinematic interaction analysis consists in evaluating the 6 displacements of the master node ( 3 translations and 3 rotations) due to the shear waves propagating through the deposit. 

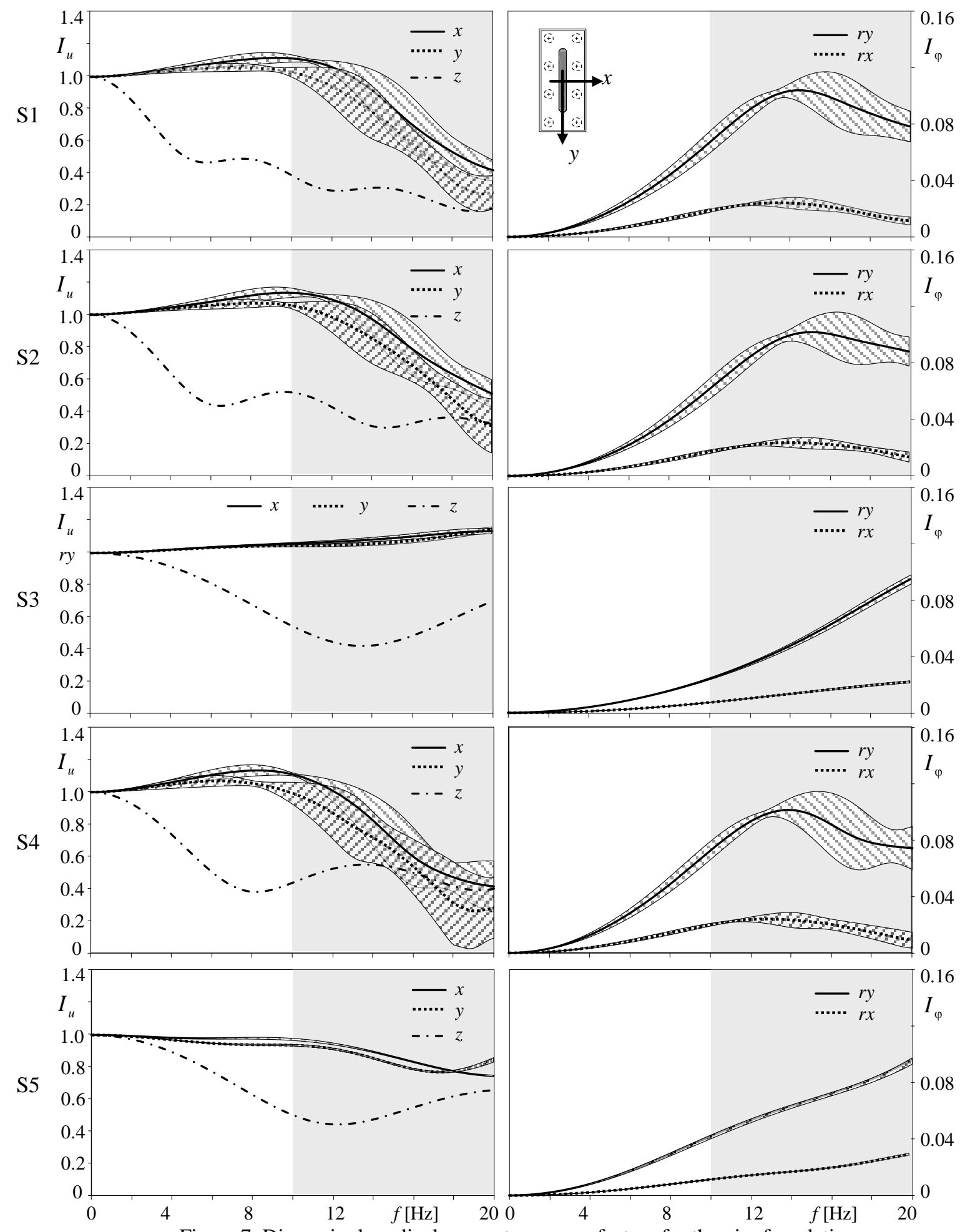

These displacements constitute the motion at the base of each pier and abutment and result from the filtering action exerted by the deposit and the deep foundation. Compared with the free-field motion at the outcropping soil, higher frequencies of translations are cut off but rotational components are generated by the presence of the foundation. The filtering effect of the soil-foundation system for the five stratigraphies considered in this work is shown in Figure 7 where the dimensionless displacement response factors 


$$
\begin{aligned}
I_{u, x}=\frac{d_{F I M, x}}{d_{f f, x}} & I_{u, y}=\frac{d_{F I M, y}}{d_{f f, y}} \\
I_{\varphi, r x}=\frac{d_{F I M, r x} D}{d_{f f, y}} & I_{\varphi, r y}=\frac{d_{F I M, r y} D}{d_{f f f, x}}
\end{aligned}
$$

are reported. In equations (2) and (3), $D$ is the pile diameter and subscripts $x$ and $y$ refer to the displacement components of the rigid cap $\left(d_{F I M}\right)$ and the free-field $\left(d_{f f}\right)$ at ground surface, respectively, whereas $r x$ and $r y$ refer to the rotation components of the rigid cap. It is worth noting that, since the soil mechanical properties depend on the shear strain amplitudes, different response factors are associated to each accelerogram. Figure 7 shows the mean curves with the standard deviations, obtained with the considered set of accelerograms, in which major scattering are evident for frequencies higher than $10 \mathrm{~Hz}$. Displacements in the two directions, even if scattered, are sensibly similar, whereas rotations referred to the $y$ axis are more than three times higher than those referred to the $x$ axis, due to the foundation configuration and geometry. Finally, the results for vertical displacements are not scattered since nonlinear behaviour of the soil was not simulated for the lack of information about properties' degradation.

A second outcome of the soil-foundation system analysis is the frequency-dependent impedance matrix for each foundation. Due to the pile layout symmetry, this assumes the form

$$
\mathfrak{I}=\left[\begin{array}{cccccc}
\mathfrak{I}_{x} & 0 & 0 & 0 & \mathfrak{I}_{x-r y} & 0 \\
& \mathfrak{I}_{y} & 0 & \mathfrak{I}_{y-r x} & 0 & 0 \\
& & \mathfrak{I}_{z} & 0 & 0 & 0 \\
& & & \mathfrak{I}_{r x} & 0 & 0 \\
& \operatorname{sym} & & & \mathfrak{I}_{r y} & 0 \\
& & & & & \mathfrak{I}_{r z}
\end{array}\right]
$$

where the only non-null coupling terms are the roto-translational components. Examples of the foundation impedances are reported by Figure 8 for the pier foundation (continuous lines) in soil profile $S 1$.

\subsection{Analysis of the superstructure}

The second step of analysis is constituted by the inertial interaction analysis that is carried out considering the structure on frequency dependent compliant restraints. To take advantage of common computer codes, which generally allows only for time domain analyses, the SSI problem has to be studied by introducing frequency independent quantities. To reproduce the frequency dependent impedances of the soil-foundation system, LPMs constituted by springs, dashpots and masses, assembled and calibrated so as to reproduce the frequency dependent impedances of the soil-foundation system [17], are used in this work. These allow to account for the soil radiation damping.

For this purpose, three-dimensional finite element models are developed in SAP2000® [18] (Figure 9a). Piers are considered to be beam elements with variable cross section in order to account for their actual geometry. Beam elements are also used to model the steel-concrete composite deck accounting for the change of steel plate thicknesses along the deck. Isolators are modelled with twojoint viscoelastic link elements to take into account the device thickness. The effective horizontal stiffness of the devices $\left(k_{\text {eff }}\right)$ is used for the links while the damping coefficients are calibrated starting from the well known expression

$$
c=\xi \frac{2 k_{\text {eff }}}{\omega_{0}}
$$


where $\omega_{0}$ is the fundamental frequency of the isolated bridge and $\xi$ is the equivalent damping factor; 5\% additional structural damping for the superior modes is introduced by the Rayleigh method.
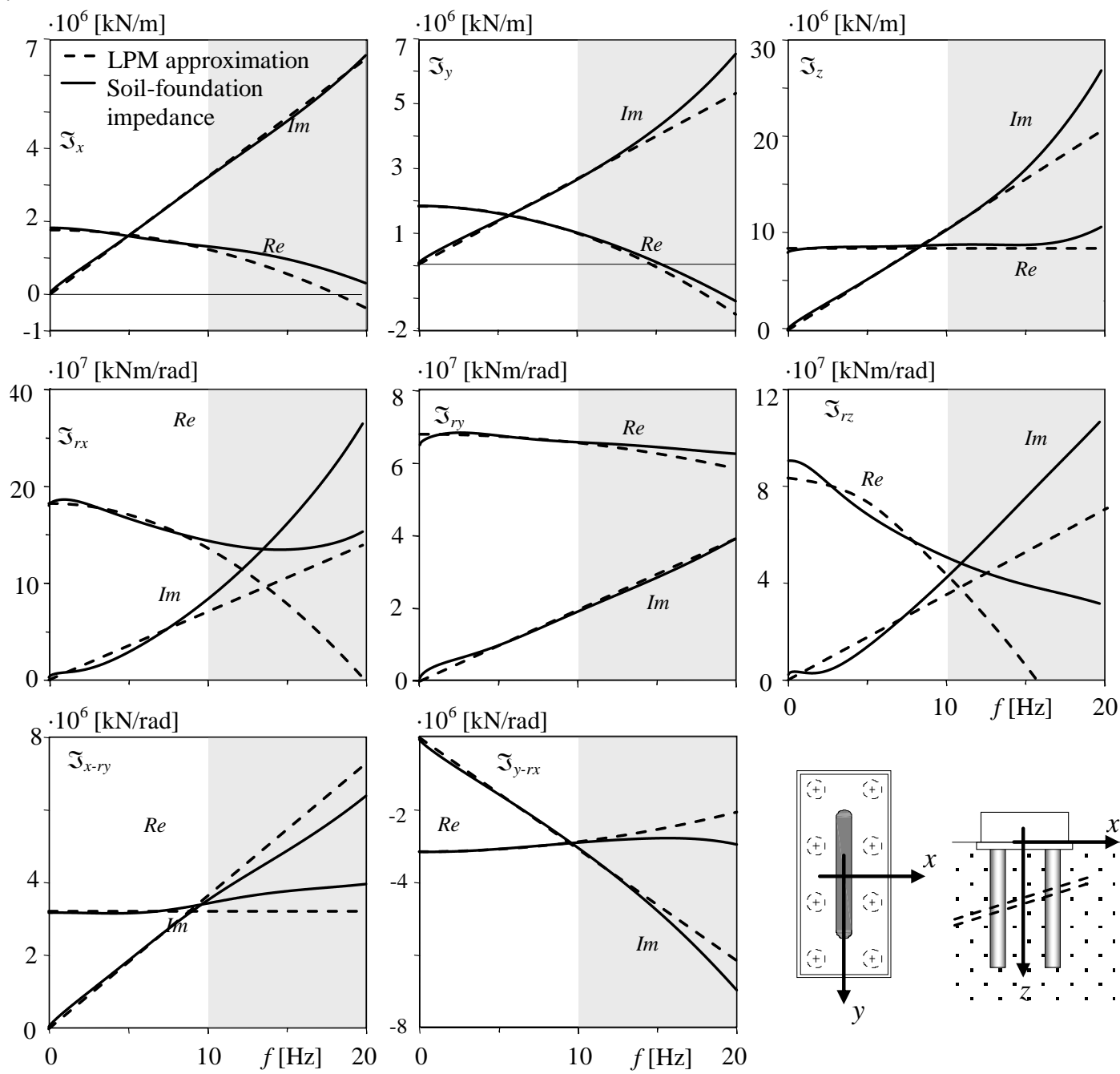

Figure 8. Non-null components of the impedance matrix of the pier soil-foundation system (soil profile S1)
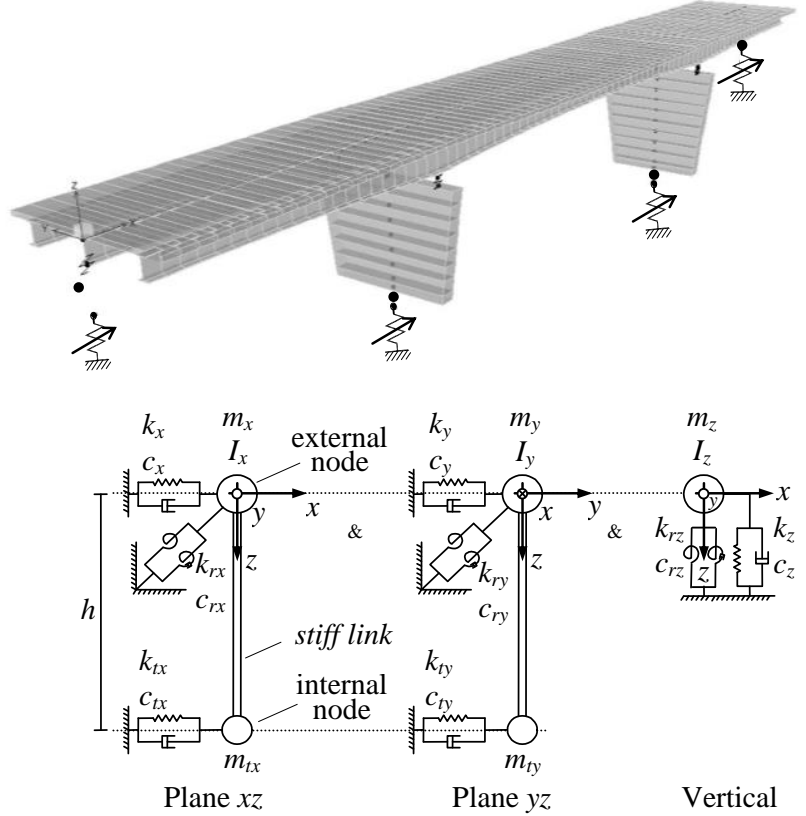

(b)

Figure 9. Model for the inertial interaction analysis: (a) finite element model (b) Lumped Parameter Model 
As for the soil-foundation system, the frequency dependent dynamic behaviour is taken into account introducing a suitable LPM able to approximate the diagonal and out-of-diagonal terms of the impedance matrix (4). A 6 degree of freedom LPM is constructed, for each foundation, as depicted in Figure 9b. The components of the impedance matrix of the LPM are $(\alpha=x, y)$

$$
\begin{aligned}
& \tilde{\mathfrak{I}}_{\alpha}(\omega)=\left[k_{\alpha}+k_{t \alpha}-\omega^{2}\left(m_{\alpha}+m_{t \alpha}\right)\right]+i \omega\left(c_{\alpha}+c_{t \alpha}\right) \\
& \tilde{\mathfrak{I}}_{r \alpha}(\omega)=\left[k_{r \alpha}+k_{t \alpha} h^{2}-\omega^{2} I_{\alpha}\right]+i \omega\left(c_{r \alpha}+c_{t \alpha} h^{2}\right) \\
& \tilde{\mathfrak{I}}_{z}(\omega)=\left[k_{z}-\omega^{2} m_{z}\right]+i \omega c_{z} \\
& \tilde{\mathfrak{I}}_{r z}(\omega)=\left[k_{r z}-\omega^{2} I_{z}\right]+i \omega c_{r z} \\
& \tilde{\mathfrak{I}}_{x-r y}(\omega)=h\left(k_{t x}-\omega^{2} m_{t x}+i \omega c_{t x}\right) \\
& \tilde{\mathfrak{I}}_{y-r x}(\omega)=h\left(k_{t y}-\omega^{2} m_{t y}+i \omega c_{t y}\right)
\end{aligned}
$$

The 25 constants are calibrated with a least squares procedure in order to achieve the better approximation of the impedance functions in the frequency range $0 \div 10 \mathrm{~Hz}$. Figure 8 shows, with dashed lines, the non-null components of the LPM impedance matrix for the stratigraphy S1 evaluated by equations (6).

\section{MAIN RESULTS}

SSI analyses of the Isolated (I) bridge are performed and the results are compared with those obtained from a conventional fixed base approach. Furthermore, in order to better appreciate SSI effects on the isolated structure, SSI analyses of the Non-Isolated (NI) bridge are also performed. A Fixed Base (FB) model, fully restrained at the base of the piers, and a Compliant Base (CB) model are developed for the I and NI bridges. The seismic input for the CB models is derived starting from the FIMs obtained from the kinematic interaction analysis. For the FB models the ten triplets of accelerograms achieved at ground surface by the local response analyses are used as input motions.

\subsection{Structural deformability}

The SSI effects on the overall structural deformability are investigated by means of steady-state analyses in which unit point harmonic loads are applied at the middle node of the deck as depicted in Figure 10. Such analyses allow evaluating the fundamental frequencies of the structures consistently with their non-classically damped nature. Figure 10 shows the amplitude of the displacement response in the longitudinal, transverse and vertical directions, measured at the loaded point for all the soil profiles, and normalized with respect to the maximum values (absolute values are also reported within the graph area). For the I bridge, it is evident that SSI does not affect very much the fundamental frequencies of the structure to such an extent that curves appear almost superimposed. On the contrary, in the case of NI bridges some important differences may be observed with reference to the horizontal response of the bridge; in particular, as a consequence of the high transverse stiffness of the piers, SSI modifies sensibly the fundamental frequencies in the transverse direction, revealing that the system behaviour is strongly sensitive to the presence of compliant restraints. However, differences between frequency shifts relevant to each soil profile are less significant. This was not observed in the I bridges because the stiffnesses of the isolation units, which are significantly lower than those of the foundations and substructures, maintains the first vibration modes unaffected by the foundation compliance.

The contribution of radiation damping to the response of I and NI bridges is not evident as height and widths of peaks are almost the same, expecting the transverse response of the NI bridges. 


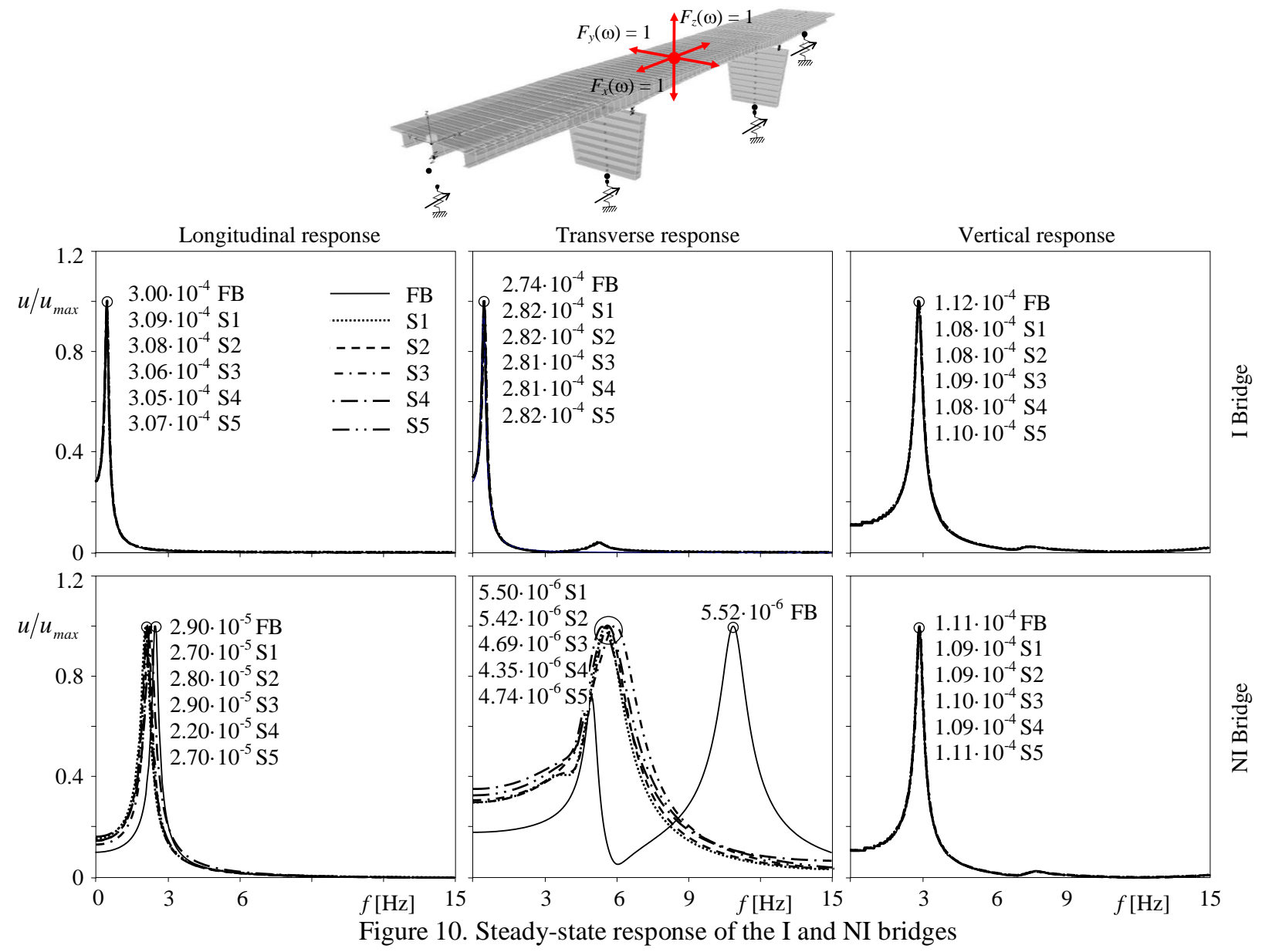

\subsection{Isolator deformations}

During earthquakes, isolators undergo deformations due to the relative displacements and rotations between the top and bottom anchor plates (one connected to the top of the piers and the other to the bottom of the deck beams). Due to the horizontal components of the ground motion, relative displacements between deck and piers, pier deflections and, consequently, rotations of the pier top arise, while, due to the vertical components, vertical vibrations are induced to the bridge deck; these are responsible for further rotations of the beams in correspondence of the supports. Thus, isolator horizontal displacements are mainly due to the earthquake horizontal components whereas the isolator rotations are due to both horizontal and vertical components. Furthermore, for decks supported by wall-type piers, as the ones here examined, displacements in the transverse direction do not produce significant rotations of the isolation units.

Figure 11 shows the maximum displacement $d$ of an edge isolation unit of pier P1 (for pier P2 results are almost the same) and the maximum rotation $\phi$ of the edge isolators of both piers P1 and $\mathrm{P} 2$. These are evaluated as maximum relative displacements between the top of the pier and the deck beam at supports, accounting for the spatial components of the motion. Displacements and rotations obtained by the $\mathrm{CB}$ models are normalized with respect to the results of the FB models; the mean values are reported with dashed lines.

SSI slightly affects the maximum displacements of the devices whereas significantly influences the maximum rotations. For stratigraphies S1, S2 and S4, the mean rotation values are lower than those obtained by the FB model (dashed lines are below the continuous ones), whereas for stratigraphies S3 and S5 are slightly higher.

Concerning displacements, results can be explained observing the horizontal components of the displacement response factors $I_{u}$ of Figure 7 . In the frequency range $0 \div 10 \mathrm{~Hz}$, the free-field ground 
surface displacements are slightly magnified by SSI and consequently the SSI model leads to higher lateral displacements than those obtained using the FB model (dashed lines are over the continuous ones for all the soil profiles).

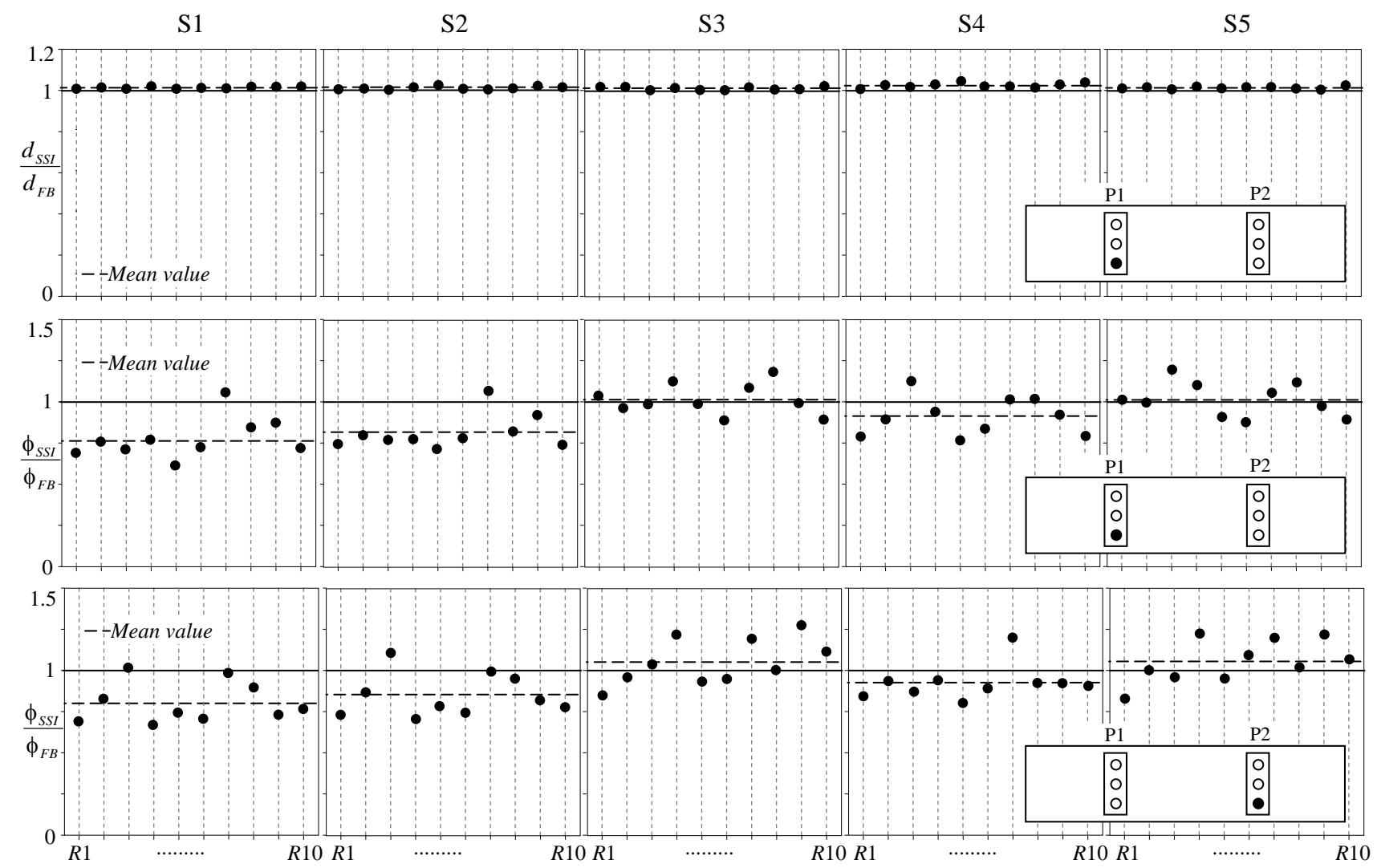

Figure 11. Normalised displacements and rotations of edge isolators of piers P1 and P2

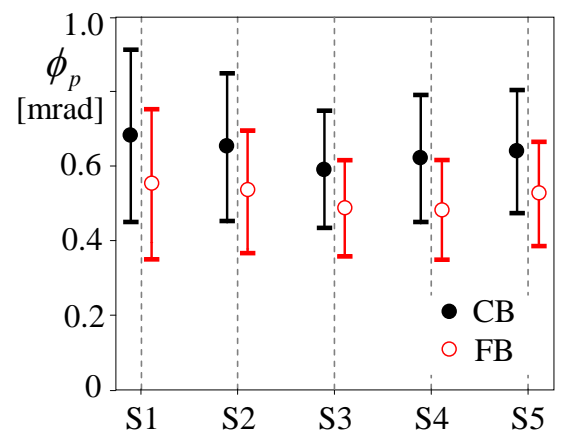

(a)

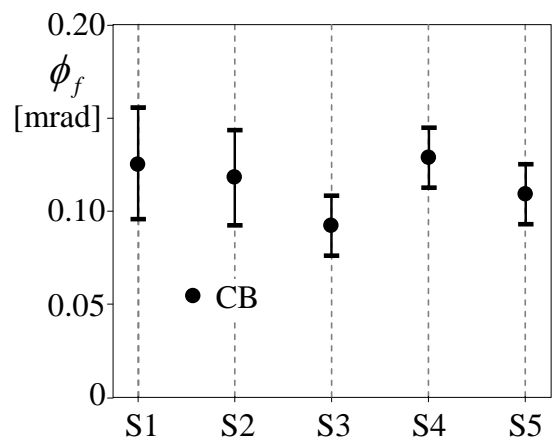

(c)

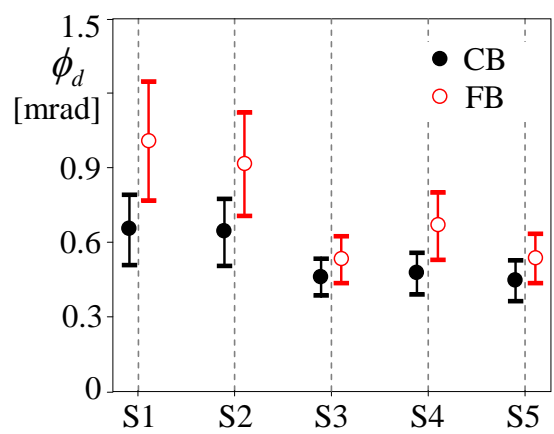

(b)

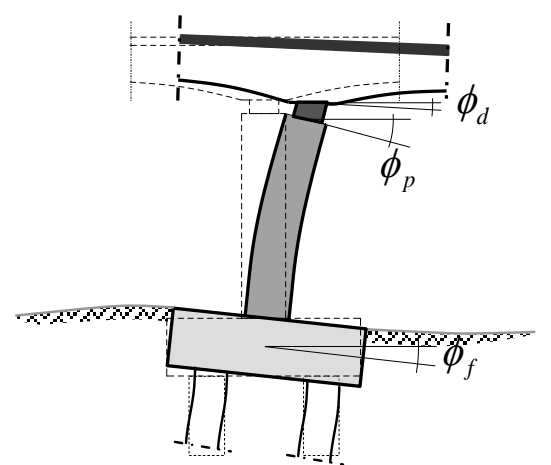

(d)

Figure 12. (a) Mean rotations of the bottom plate; (b) mean rotations of the top plate; (c) foundation rocking; (d) rotation components 


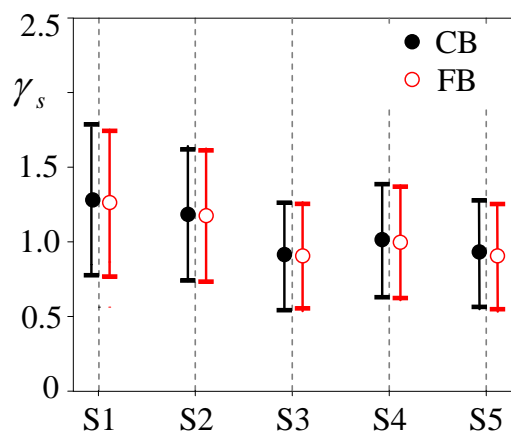

(a)

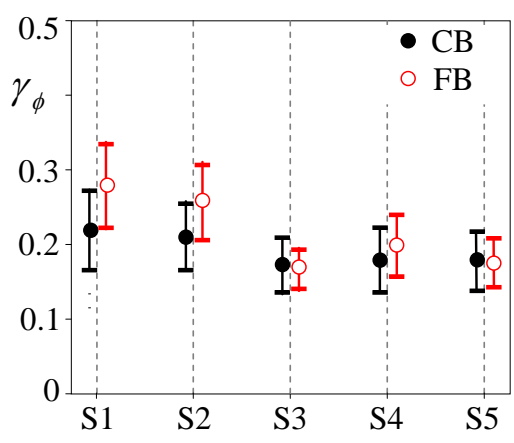

(b)

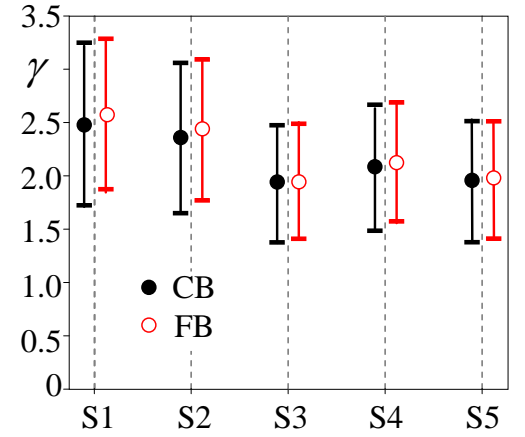

(c)

Figure 13. Isolator shear strains: (a) displacement component; (b) rotation component; (c) total strain

Concerning the rotation of the isolators, the results interpretation is less explicit because, as already pointed out, rotations are due to both horizontal and vertical ground motions. Figure 12a-b shows the mean rotations and the relevant standard deviations of the top of one pier and of the deck at the support. Furthermore, Figure 12c shows the mean foundation rocking about the transverse direction $y$ obtained with the SSI model (the rocking is null, in the case of FB models). It can be observed that SSI induces opposite effects: an increment of the rotations of the top of the piers and a reduction of the rotations of the deck. The first is due to the horizontal components of the ground motions and to the foundation rocking that causes a rigid rotation of the pier (see Figure 12d). The second is due to the vertical components of the foundation input motion that, as can be observed from the vertical displacement response factors of Figure 7, are lower than the free-field ground surface displacements and produce lower rotations of the deck in the case of the SSI model, compared with those obtained with the FB model. In particular, taking into account that the first vertical frequency of the bridge is about $3 \mathrm{~Hz}$ for both CB and FB models (Figure 10), the reduction is more important for the softest stratigraphies $\mathrm{S} 1, \mathrm{~S} 2$ and $\mathrm{S} 4$.

Given the previous considerations, in Figure 11, for soil profiles S1, S2 and S4, isolator rotations are essentially due to the deck rotations that prevail on the pier top; the opposite takes place for soil profiles S3 and S5.

The total shear strain $\gamma$ in the isolators is computed summating three contributions: the seismic displacement $\gamma_{s}$, the angular rotation $\gamma_{\phi}$ and the axial compression $\gamma_{c}$, evaluated according to expressions

$\gamma_{s}=\frac{d}{t_{e}}$

$\gamma_{\phi}=\frac{3 D^{2}}{8 t_{i} t_{e}} \phi$

$\gamma_{c}=\frac{1.5}{s G_{d y n} A_{r}} N$

in which $t_{e}$ is the total thickness of the elastomeric layers, $t_{i}$ is the thickness of the single layer, $N$ is the seismic axial force in the device, $s$ and $A_{r}$ are shape factors and $G_{d y n}$ is the equivalent dynamic shear modulus.

Figure 14 shows a comparison between the maximum shear strains obtained evidencing the contributions of the first two components (Figure 14a and b). Mean values are reported with dots whereas the vertical segments represent the standard deviation values. It is evident that the component relevant to rotation is more sensitive to SSI but this is not reflected on the global shear strain that is only slightly influenced. 


\subsection{Base shears}

Figure 15 shows the ratio between the pier maximum base shear for the $\mathrm{CB}$ and the FB models, in the longitudinal and transverse directions obtained with the ten accelerograms for the five stratigraphies. Both I and NI bridges are considered. The mean values of the ratios are also reported in each graph with a dashed line. It is worth noting that in the case of the I bridge SSI slightly affects the behaviour of the structure: the average base shears obtained from the CB model are about $10 \%$ higher than those achieved with the FB model in both longitudinal and transverse directions, as a consequence of the higher horizontal displacements. On the contrary, in the case of NI bridges, SSI produces important modifications on the shear forces and large variability from one record to the other is observed. In particular, in the longitudinal direction, a reduction of the base shear is evident while in the transverse direction important increments, sometimes greater than $30 \%$ of the values obtained by the FB model, are evident; these increments are justified by the shift of fundamental periods towards ranges with higher spectral accelerations.

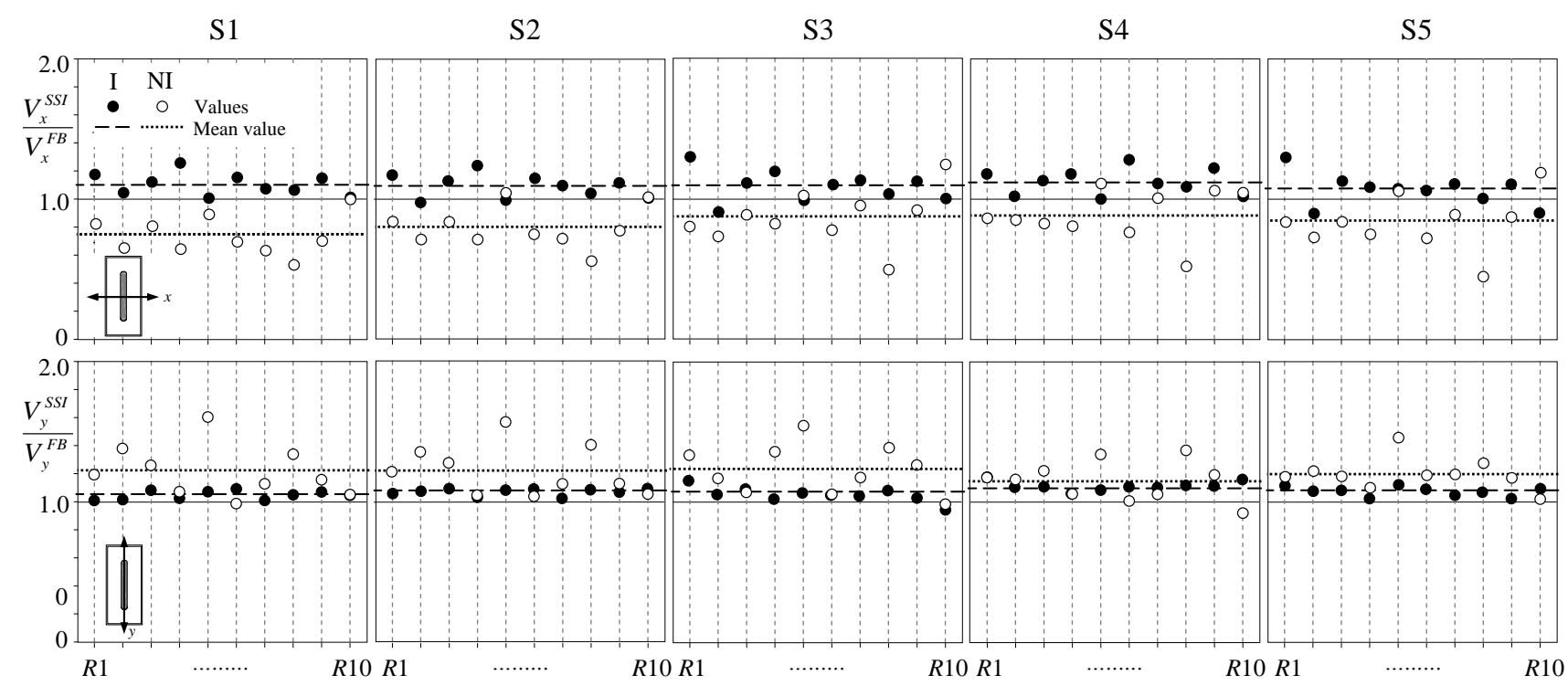

Figure 14. Pier base shears obtained with the ten accelerograms
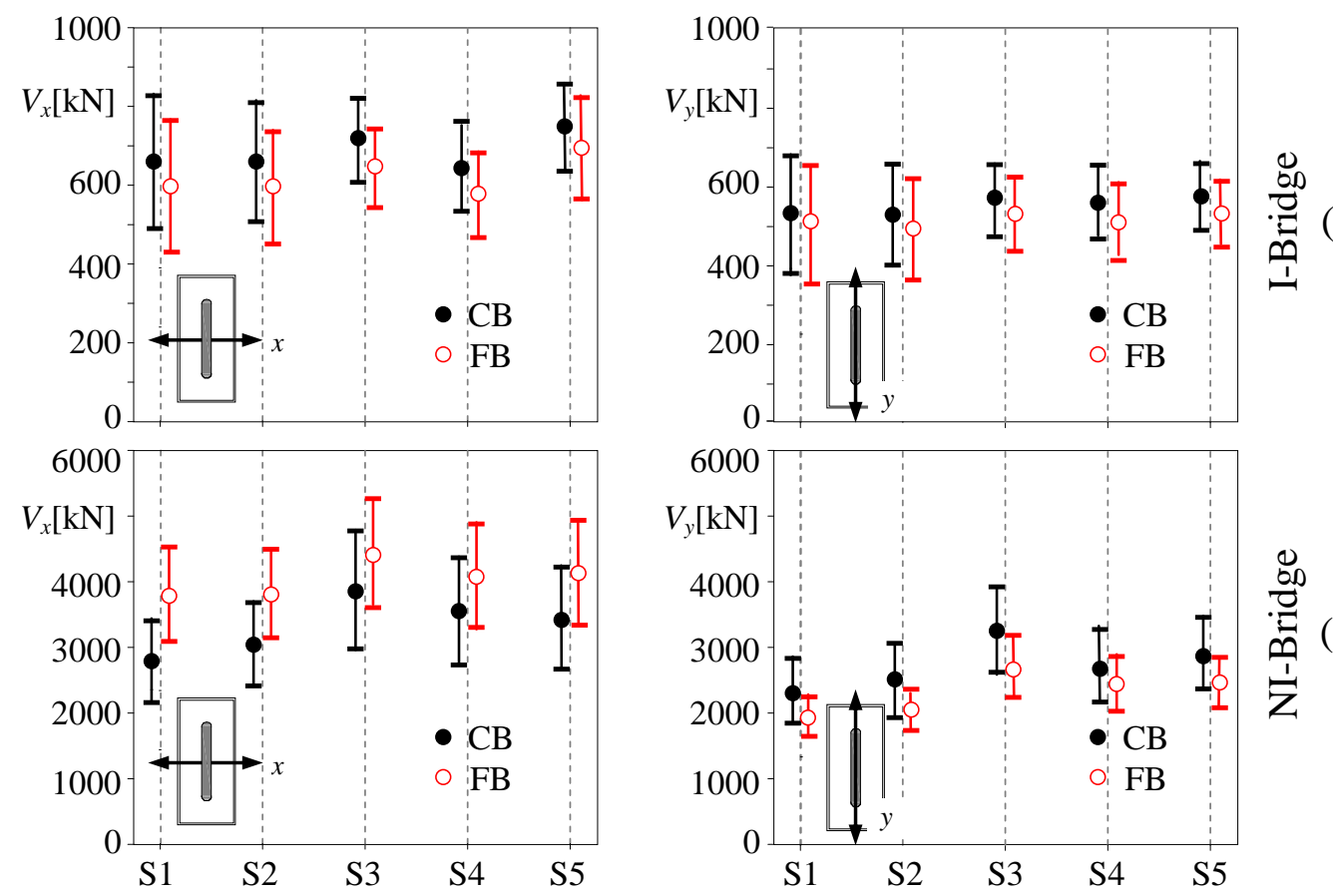

Figure 15. Average pier base shears for the I and NI bridges: (a) longitudinal direction; (b) transverse direction 
Figure 16 shows the average values with the standard deviation obtained for the I and NI bridges. As for I bridges (Figure 16a), in the longitudinal direction the base shear undergoes a higher increase compared with that in the transverse direction. Furthermore, the effects of the different site amplifications are responsible for a higher scattering of the results in the longitudinal direction. Higher values of the base shear are obtained with soil profiles having the outcropping stratum with the higher $\mathrm{V}_{\mathrm{s}}$.

Figure 16b shows results for the NI bridges. As expected, the base shears are much higher than those obtained for the I bridges (about five times) demonstrating the efficiency of the base isolation technique in reducing structural forces. It is worth also noting that results are more scattered than those relevant to the I bridges. In fact, as already observed in Figure 10, SSI modifies sensibly the bridge fundamental periods and consequently, depending on the seismic action, different spectral accelerations are responsible for the scattered values.

\section{CONCLUSIONS}

Effects of SSI on the seismic behaviour of isolated three span overcrossings founded on piles have been investigated by considering typical real bridges along the A14 Motorway in central Italy. All the analyses are based on a comprehensive geotechnical characterization of the site from which dynamic and mechanical properties of the soil profile are evaluated.

To capture the site amplification effects and the free-field motions within the deposits, multiple independent site response analyses at each pier and abutment location are performed, by processing ten triplets of real accelerograms opportunely defined at the outcropping bedrock.

The SSI analyses are carried out by means of the substructure technique, performing the kinematic interaction analysis of each soil-pile foundation system in the frequency domain and the superstructure inertial interaction analysis in the time domain after having implemented suitable Lumped Parameter Models (LPMs) to account for the frequency dependent soil-foundation compliance of each pier and abutment.

SSI effects on the seismic response of the bridge are evaluated comparing the results with those derived from a conventional fixed base model. Furthermore, in order to highlight differences with non-isolated bridges, responses of fixed base and compliance base models of the non-isolated bridge are analyzed.

From the obtained results the following observations can be drawn:

- the isolated bridges, from a global point of view, are less sensitive to SSI effects than the non isolated ones; the foundation flexibility and the radiation damping slightly affects the fundamental frequencies and the overall dynamic behaviour of the isolated bridges, as well as the pier base shear in both the longitudinal and transverse directions;

- angular rotations of isolators strongly depend on the deck rotations and the foundation rocking; for a reliable evaluation of relative rotations between the pier top and the deck both horizontal and vertical components of the earthquake excitation have to be considered in the seismic analysis as well as SSI effects;

- SSI slightly increases the maximum relative displacements of the isolation devices;

- in the non isolated bridges, as expected, SSI affects significantly the overall dynamic behaviour of the bridges, by increasing the transverse base shear and decreasing the longitudinal base shear.

\section{REFERENCES}

[1] Ghobarah, A., Ali, H.M., 1988. Seismic performance of highway bridges, Engng Struct, 10(3), 157-66. 
[2] Turkington, D.H., Carr, A.J., Cooke, N., Moss, P.J., 1988. Seismic design of bridges on leadrubber bearings, J Struct Engng, ASCE, 115(12), 3000-16.

[3] Saiidi, M., Maragakis, E., Griffin, G., 1999. Effect of base isolation on seismic response of multi-column bridges. Struct Engng Mech, 8(4), 411-19.

[4] Tongaonkar, N.P., Jangid, R.S., 2000. Earthquake response of seismically isolated bridges. Eur Earthquake Engng, 14, 48-58.

[5] Thakkar, S. K., Maheshwari, R., 1995. Study of seismic base isolation of bridge considering soil structure interaction, Third Int. Conf. on Recent Advances in Geotechnical Earthquake Engineering and Soil Dynamics, Univ. of Missouri-Rolla, Rolla, Missouri, Vol. 1, 397 - 400.

[6] Chaudhary, M.T.A., Abe, M., Fujino, Y., 2001. Identification of soil-structure interaction effect in base-isolated bridges from earthquake records. Soil Dynamics and Earthquake Engineering, 21(8), 713-25.

[7] Tongaonkar, N.P., Jangid, R.S., 2003. Seismic response of isolated bridges with soilstructure-interaction. Soil Dynamics and Earthquake Engineering, 23(4), 287-302.

[8] NTC2008 Technical rules for constructions. (in Italian)

[9] Facciorusso, J., Madiai, C., 2007. Local seismic response prediction and design building code provisions: the case study of Senigallia, Italy. Proc. ERTC-12 Special Session of XIV European Conference on Soil Mechanics and Geotechnical Engineering (ECSMGE), Madrid.

[10] Valensise, G., Pantosti, D., 2001. Database of Potential sources for Earthquakes larger than M 5.5 in Italy. Annali di Geofisica. 44(4).

[11] INGV 2004. Macroseismic Italian Database. http://esse1.mi.ingv.it/

[12] Ambraseys, N., Smit, P., Sigbjornsson, R., Suhadolc, P. and Margaris, B., 2002. Internet-Site for European Strong-Motion Data, European Commission, Research-Directorate General, Environment and Climate Programme.

[13] Crespellani, T., Simoni, G., 2007. Dynamic shear stiffness and damping measurements for seismic response analyses at Senigallia, Italy. Proc. ERTC-12 Special Session of XIV European Conference on Soil Mechanics and Geotechnical Engineering (ECSMGE), Madrid.

[14] Vucetic, M., Dobry, R., 1991. Effect of Soil Plasticity on Cyclic Response, Journal of the Geoechnical Engineering Division, ASCE, 117(1), 89-107.

[15] Carbonari, S., Dezi, F., Leoni, G., 2011. Seismic soil-structure interaction in multi-span bridges: application to a railway bridge. Earthquake Engineering and Structural Dynamics, 40(11), 1219-1239.

[16] Dezi, F., Carbonari, S., Leoni, G., 2009. A model for the 3D kinematic interaction analysis of pile groups in layered soils, Earthquake Engng. Struct. Dyn., 38(11), 1281-1305.

[17] Wolf, J. P., 1994. Foundation vibration analysis using simple physical models. Prentice-Hall, Englewood Cliffs, N.J.

[18] Computer and Structures, 2005 CSI analysis reference manual. SAP 2000, Berkeley (CA). 